question. While an analysis of variance with repeated measures over trials would seem most appropriate, $t$ tests were performed. Figure 2 of McCain's paper seems to reflect a Reward by Days interaction resulting from a slower rate of extinction for the large-reward group. Such an interaction might be borne out by the appropriate statistical analysis.

McCain did recognize that "during acquisition, magnitude differences disappear under some conditions" (italics ours). He further recognized that "a number of possible confounding variables such as drive level, strain of animals, sampling, weight of Ss, particular reward magnitudes, pretraining, and performance within days are obvious. Any or all of these could explain the results." He, nevertheless, drew the sweeping conclusion that "after about 60 consistently reinforced acquisition trials in a straight alley, the acquisition effects of different reward magnitudes are either minimal or absent," and went on to challenge "most learning theories."

It seems to us that the results of both experiments could be interpreted entirely in terms of drive level, sex differences, weight of Ss, and performance within days. In this light, McCain's results contribute little to our knowledge that "under some conditions" the long-standing findings about reward magnitude during acquisition do not hold. However, if the effects of reward magnitude do, indeed, disappear with extended training while the factors we have mentioned are adequately controlled, then we certainly should be forced to revise some of our theoretical notions.

REFERENCES

AMSEL, A. Partial reinforcement effects of vigor and persistence. In $K$. W. Spence and J. T. Spence (Eds.), The psychology of learning and motivation. New York: Academic Press, 1967.

HILL, W. \& WALLACE, W. Reward magnitude and number of training trials as joint factors in extinction. Psychonomic Science, 1967, 7, 267-268.

McCAIN, G. Reward magnitude and instrumental responses: Consistent and partial reward. Psychonomic Science, $1970,19,139-140$. PUBOLS, B. Incentive magnitude, leaming, and performance in animals. Psychological Bulletin, 1960, 57, 89-115.

SEWARD, J. P., SHEA, R. A., ELKIND, D. Evidence for the interaction of drive and reward. American Joumal of Psychology, $1958,71,404-407$.

WAGNER, A. R. Effects of amount and percentage of reinforcement and number of acquisition trials on conditioning and extinction. Journal of Experimental Psychology, 1961, 62, 234-242.

\section{Traupmann and Wong: A reply}

\author{
GARVIN McCAIN \\ University of Texas at Arlington, Arlington, Tex. 76010
}

It is always gratifying to know that there are those out there who read, even disapprovingly, your written efforts.

In their first paragraph, Trapumann and Wong quote me, “... are not sufficient to convince anyone that the effects of reward magnitude are sharply decreased or disappear after extended training." So far, so good. It would have been even better if they had also quoted the first part of that sentence, "Taken alone, these two studies..." and the next three sentences," "A series of nine other [italics added] consistent reward studies has been run in our laboratory. Six of these studies have been put into one paper that is now under editorial consideration. In addition, Black (in press) and Bloom \& Milstead (1969) have substantial evidence that, during acquisition, magnitude differences disappear under some conditions." Black presented eight studies (now in print, 1970) and Bloom and Milstead two studies. In brief, I had considered a substantial number of failures to find asymptotic differences related to magnitude before rushing into print with two short studies.
There are other quotations that might have been extended. Perhaps those interested in this discussion would be well advised to read the original article (McCain, 1970).

The present reply does not represent an attempt to answer the detailed criticisms of Traupmann and Wong. I believe these will be best answered by presentation of the entire series of studies. In the original study, I listed seven possible confounding variables, "... such as, drive level, strain of animals, sampling, weight of Ss, particular reward magnitudes, pretraining, and performance within days, are obvious." We might note that these constitute virtually an outline of Traupmann and Wong. As stated in the article, I am hopeful that presentation of all of our data will resolve some of these problems.

Perhaps I was remiss in failing to list other problems or points that need discussion in these two studies and in other magnitude studies. For example, there is an obvious need for a sequential analysis or control of the sequential probabilities in the partial-reinforcement study (Experiment 2). Again, there is no

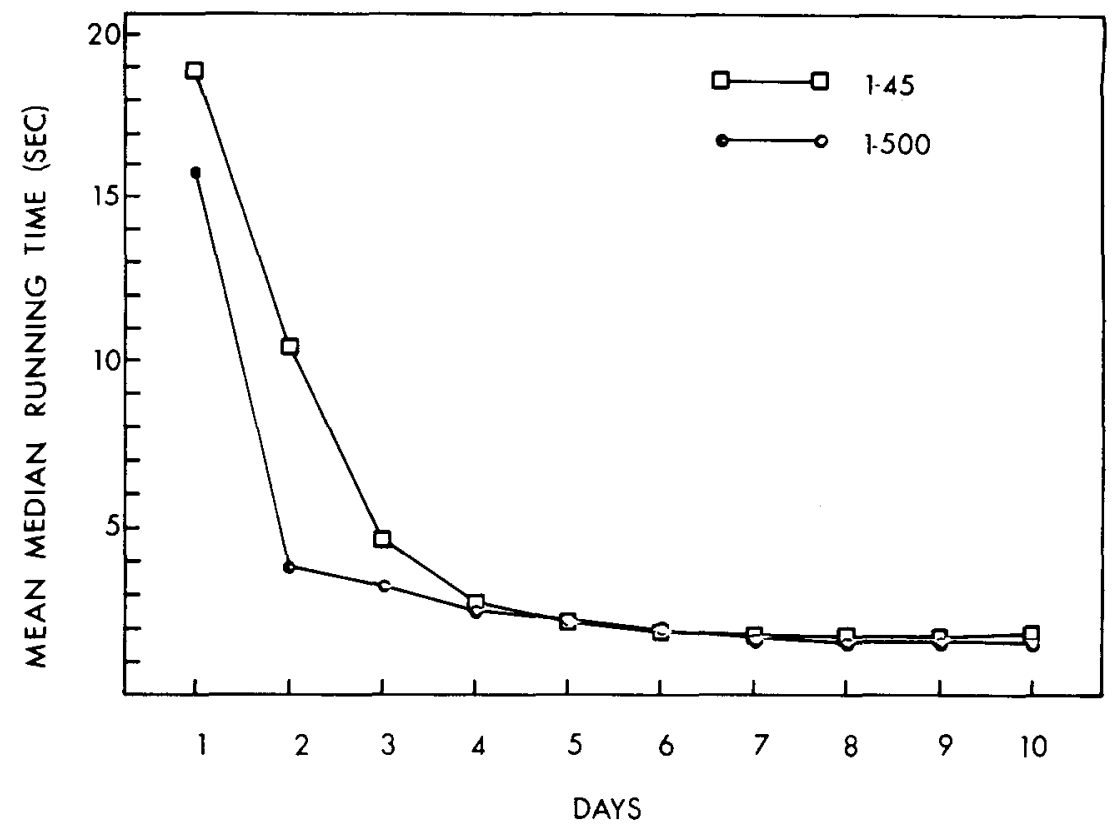

Fig. 1. 
mention of odor control, although Ludvigson and his colleagues (e.g., Morrison \& Ludvigson, 1970) have clearly demonstrated its importance. The list could be even longer.

Not only do we have to worry about the "possible confounding variables" mentioned in the original study, but also we have to recognize that all magnitude studies to date are potentially confounded. Deese \& Hulse (1967, p. 43-44) consider these problems at greater length than is possible here. One example of a confounding variable is the length of time the $\mathrm{S}$ is exposed to the goalbox stimuli.

There are additional studies, not cited in the original article, in which asymptotic differences related to magnitude failed to appear. Meyers (1968) concluded that "... reward magnitude is essentially a growth rate parameter but does not determine the eventual asymptote of the acquisition function." Spear and his colleagues at Rutgers (Vogel, Mikulka, \& Spear, 1966; Spear \& Pavlik, 1966; Spear \& Spitzner, 1966, 1968, 1969a, b) have some evidence that seems worth considering. Spear (personal communication) comments, "I have enclosed some reprints including examples in which no differences in running speeds occurred in late acquisition in spite of large reinforcer differences (number of food pellets). Most of our other published papers, especially with the T-maze, have similar examples." I do not imply that Spear accepts the general statement that there are no asymptotic differences due to reinforcer magnitude. That is not the case. McHose and his colleagues at Southern Illinois (personal communication) have a series of unpublished studies in which they found no asymptotic differences related to magnitude. There are a number of other such instances in earlier literature (e.g., Gonzales, Gleitman, \& Bitterman, 1962; Snyder \& Hulse, 1961; Miller \& Estes, 1961).

I am not attempting to make the case for the lack of asymptotic differences by citation. The point is that a substantial number of experienced $E s$ in a large number of studies do not get evidence for asymptotic differences. Whatever the shortcomings of the two original studies, it seems unlikely that all those involved have made the same or overlapping errors.

Traupmann and Wong do raise a specific question regarding the use of reciprocal transformations. This question is not considered directly in the monograph and might be worth some comment. I have reanalyzed Experiment 2 (partial reinforcement) using the suggested transformation. The differences are still not significant. As noted in the original article, I viewed Experiment 2 with extreme caution, since it was a single study. I place more weight on consistent reinforcement studies, since we do have much more evidence. As may be seen in Fig. 1, from the original study, the overlap between the consistent reinforcement groups seems completely in line with the analysis $(F=1.01)$. In addition, in the six studies mentioned earlier, the small-reward group sometimes ran faster than did the large-reward group. At times one group was faster on one measure and slower on another, and at times differences were within a rounding error. How these sorts of results could be converted to significant differences by transformation of the scores escapes me at the moment.

Studies in which asymptotic differences are found (e.g., Spear \& Pavlik, 1966, or Wike \& Chen, 1970) cannot be ignored. The fact that Es have gotten asymptotic differences in a substantial number of studies, while others have failed repeatedly, should warn us that our understanding of magnitude phenomena is, at best, very limited.

We have not resolved this issue. Many questions remain. Viewing all the evidence together with Traupmann and Wong's comment, I remain convinced that under some conditions differences due to reward magnitude disappear at asymptote.

Perhaps in desperation we should go back, or just go, to the laboratory.

$$
\text { REFERENCES }
$$

BLACK, R. W. Incentive motivation and the parameters of reward in instrumental conditioning. In W. J. Arnold and D. Levine (Eds.), Nebraska symposium on motivation. Lincoln: University of Nebraska Press, 1970.

BLOOM, J M. \& MILSTEAD, J. Interactive effect of reward magnitude and intertrial interval on extinction behavior. Paper presented at Psychonomic Society meeting, November 1969.

DEESE, J., \& HULSE, S. H. The psychology of learning. New York: McGraw-Hill, 1967.

GONZALES, R. C., GLEITMAN, H., \& BITTERMAN, M. E Some observations on the depression effect. Journal of Comparative \& Physiological Psychology. $1962,55,578-581$

McCAIN, G. Reward magnitude and instrumental responses: Consistent and partial reward. Psychonomic Science, $1970,19,139-141$

MEYERS, L. S. Extinction as a joint function of reward magnitude and acquisition training. Unpublished paper derived from a dissertation submitted to Adelphi University, 1968.

MILLER, L. B., \& ESTES, B. W. Monetary reward and motivation in discrimination learning. Journal of Experimental Psychology, 1961, 61, 501-504.

MORRISON, R. R., \& LUDGIGSON, H. W. Discrimination by rats of conspecific odors of reward and nonreward. Science, 1970, 167, 904-905.

SNYDER, H. L., \& HULSE, S. H. Effect of volume of reinforcement and number of consummatory responses on licking and running behavior. Journal of Experimental Psychology, 1961, 61, 474-479.

SPEAR, N. E., \& PAVLIK, W. B. Percentage of reinforcement and reward magnitude effects in a T maze: Between and within subjects. Joumal of Experimental Psychology, 1966, 71, 521-528.

SPEAR, N. E., \& SPITZNER, J. H. Simultaneous and successive contrast effects of reward magnitude in selective learning. Psychological Monographs, 1966, Whole No. 80.

SPEAR, N. E., \& SPITZNER, J. H. Residual effects of reinforcer magnitude. Journal of Experimental Psychology, 1968, 77. 135-149.

SPEAR, N. E., \& SPITZNER, J. H. Influence of degree of training and prior reinforcer magnitude on contrast effects and resistance to extinction within $S$. Journal of Comparative and Physiological Psychology, 1969a, 68, 427.433.

SPEAR, N. E., \& SPITZNER, J. H. Simultaneous and successive shifts in reinforcer magnitude and influence of discrimination task. Journal of Comparative and Physiological Psychology, 1969b, 69, 160-165.

VOGEL, J. R., MIKULKA, P. J., \& SPEAR, N. E. Effect of interpolated extinction and level of training on the "depression effect,"Journal of Experimental Psychology, 1966, 72, 51-60.

WIKE, E. L., \& CHEN, J. Runway performance and reward magnitude. Psychonomic Science, 21, 139-140. 